\title{
MEDICINE
}

\section{FEATURES OF THE CEPHALOMETRIC PROFILE OF UKRAINIAN YOUTH BY METHODS OF RICKETTS R. M., BURSTONE C. J. AND HARVOLD E. P.}

\author{
Dmitriev M. O., Chernysh A. V., Gunas I. V. \\ National Pirogov Memorial Medical University, Vinnytsya, Ukraine
}

DOI: https://doi.org/10.31435/rsglobal_ws/30062019/6569

\begin{abstract}
ARTICLE INFO
Received: 19 April 2019

Accepted: 16 June 2019

Published: 30 June 2019

\section{KEYWORDS}

Cephalometric,

Ricketts,

Burstone,

Harvold,

Ukrainian youth.

ABSTRACT

In the article, on the basis of the previous metric characteristics of craniofacial structures using methods of Ricketts R. M., Burstone C. J. and Harvold E. P. in Ukrainian young men and women with orthognathic bite, the features of the cephalometric profile of Ukrainian young men and women were analyzed in comparison with the values of analogical indices of the data determined by the authors of these techniques on residents of other populations and ethnic groups. The established features of the cephalometric characteristics of the juvenile Ukrainian population confirm the need for the creation and further study of normative cephalometric data for various ethnic, age and gender groups of the population.
\end{abstract}

Citation: Dmitriev M. O., Chernysh A. V., Gunas I. V. (2019) Features of the Cephalometric Profile of Ukrainian youth by Methods of Ricketts R. M., Burstone C. J. and Harvold E. P. World Science. 6(46), Vol.3. doi: 10.31435/rsglobal_ws/30062019/6569

Copyright: (C) 2019 Dmitriev M. O., Chernysh A. V., Gunas I. V. This is an open-access article distributed under the terms of the Creative Commons Attribution License (CC BY). The use, distribution or reproduction in other forums is permitted, provided the original author(s) or licensor are credited and that the original publication in this journal is cited, in accordance with accepted academic practice. No use, distribution or reproduction is permitted which does not comply with these terms.

Introduction. The requirement to equalize teeth in orthodontic patients remains the most important problem in our time. Often, as a result of treatment, they want to get a good smile, which harmoniously corresponds to the correct features of the persons face [12]. In the process of growth and development of the tooth-jaw system, the upper and lower jaw in relation to the base of the skull move forward and downward. The upper jaw grows, increases in size in the sagittal direction, falls down with a slightly pronounced inclination of the front or the back. The lower jaw also grows forward in the sagittal plane, while making the rotation down. Changing the direction and dynamics of growth of the upper and lower jaw is accompanied by a violation of the adhesion of the tooth row and the ratio of bone parts $[11,15]$.

Detailed information on these abnormalities cannot be obtained in a clinical examination or after an analysis of jaw gypsum model. Diagnostic models give only an idea of the size of the teeth, dental arches and their relationship. But to answer the question about the location of the teeth in relation to the bone and soft tissue faces, the morphometric characteristics of the jaws only provides teleroentgenographic study which allows obtaining a standardized, X-ray head image for metric studies [1,13].

Accordingly, the development of the dental industry increased the technical capabilities and requirements for the correction of occlusion abnormalities, and various methods of analysis of teleroentgenograms gradually emerged that attempted to answer for a more in-depth understanding of pathology in the context of the analysis of skull structures in general. Each of the researchers offered their unique points, measurements, dependencies and normative values determined in the study of different age, composition, and ethnic belonging of groups of people. However, the normative values of the same indicators can vary significantly in different populations and ethnic groups, as proved by numerous works $[7,9,10,16,17,18,19,20]$. 
Doctors are often forced, based on their clinical experience and intuition, to use a combination of indicators from different methods and standards that they think are closer to their patients. The current situation leads to discrepancies in the pathological changes of the craniofacial structures and the actual diagnosis, the impossibility of establishing criteria for the quality of treatment and the existence of a large percentage of relapses in orthodontic pathology. Therefore, the question of the morphometric analysis of properly selected individuals with regard to age, gender and ethnicity, as well as the development of mathematical models that allow the identification of individual characteristics today are very acute and require a profound and diverse research. Well-known methods of teleroentgenographic analyzes by Ricketts R. M. [14], Burstone C. J. [3] and Harvold E. P. [8] allow obtaining a large number of valuable and useful clinical and anatomical views of diagnostic indicators.

Material and methods of research. From the data bank of the Research Center of National Pirogov Memorial Medical University, Vinnytsya taken the primary lateral cephalograms of 38 young men (aged 17-21 years) and 55 young women (aged 16 to 20 years) with normal occlusion, close to orthognathic bite and harmonic face, obtained using a CBCT Veraviewepocs 3D, Morita (Japan).

The analysis of lateral cephalograms was carried out according to Ricketts R. M. [14], Burstone C. J. [3] and Harvold E. P. [8].

Statistical processing of the received data was carried out in the licensed package "Statistica 6.0" using nonparametric methods.

Results and discussion. A detailed analysis of the metric characteristics of craniofacial structures using Ricketts R. M., Burstone C. J. and Harvold E. P. has been described by us in previous studies $[4,5,6]$.

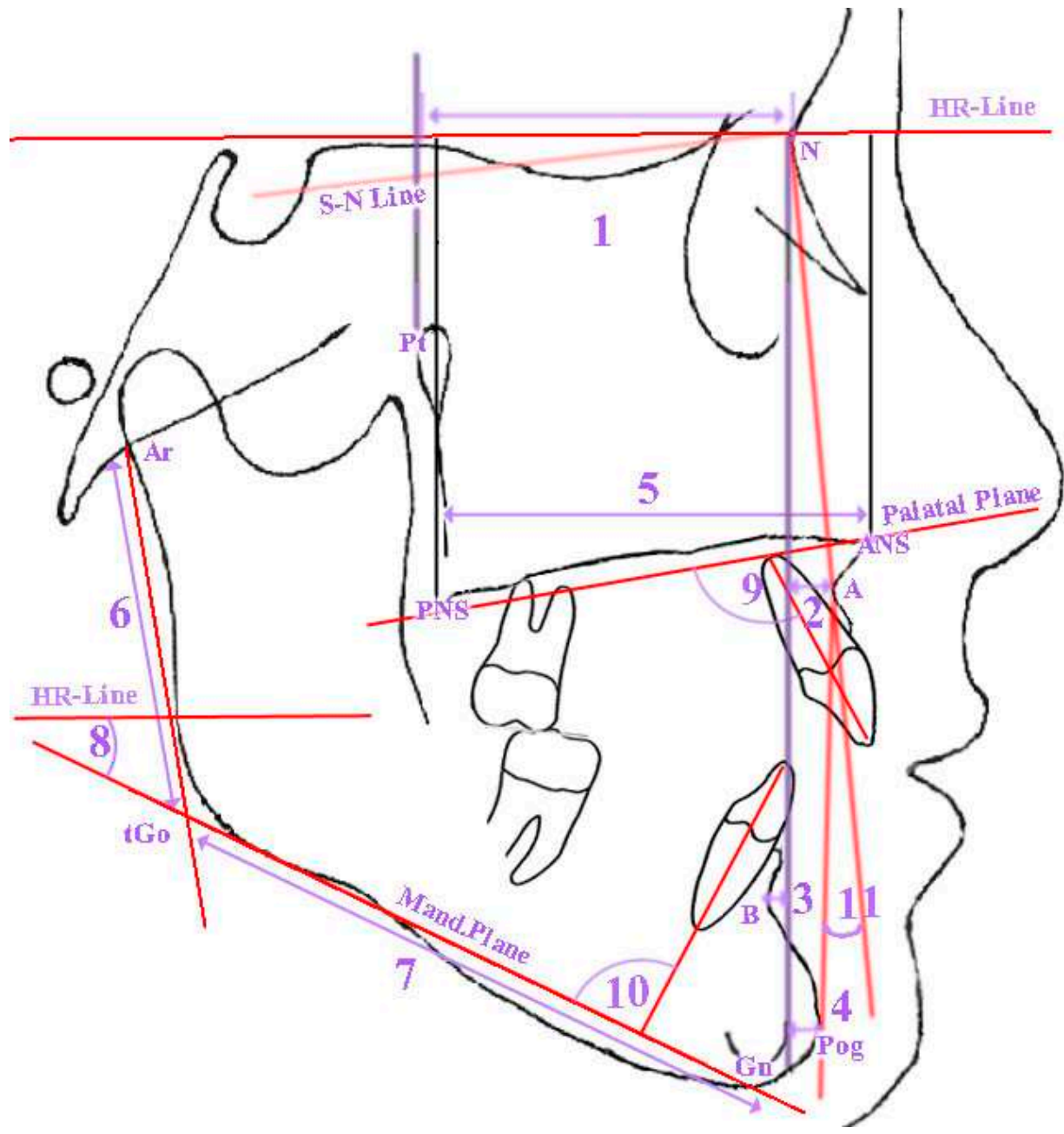

Fig. 1. Cephalometric indicators profile of Ukrainian boys with orthognathic bite by Burstone. 1 - distance Pt-N (Anterior Section of Cranial Base); 2 - distance N-A (Maxillary Position); 3 - distance N-B (Mandibular Position); 4 -distance N-Pog (Position of Chin); 5 -distance Ar-Go (Ramus Length); 6-distance ANS-PNS (Maxillary Length); 7 - distance Go-Pog (Mandibular Length); 8 -angle MP-HP

(Angle of Mand. to Horizontal Plane); 9 - angle Maxl-NF (Angle of Axis of 1u to Palatal Plane); 10 - angle Mand1-Mp (Angle of Axis of 11 to Mand. Plane); 11 - angle NAPog (Convexity). 
When analyzing the profile of Ukrainian young men with orthognathic bite, it is necessary to note the following most pronounced features in comparison with the values of these data of Burstone C. J. determined on US residents of European origin (Fig. 1):

more forward position of the frontal-nasal suture, as evidenced by the simultaneous increase in the distances Pt-N (1), N-A (2), N-B (3) and N-Pog (4) (which characterize the distances between the points $\underline{\mathbf{P t}}, \underline{\mathbf{A}}, \underline{\mathbf{B}}, \underline{\mathbf{P o g}}$ and $\underline{\mathbf{N}}$ along the Burstone line), and the absence of significant changes in the values of the angular value of NAPog (11) can be attributed to its lower sensitivity to the characteristics of the horizontal location of the point $\underline{\mathbf{N}}$;

more horizontal position of the body of the mandible, which is characterized by a decrease in the angle MP-HP (8). Among the indicators that characterize the size of the jaws and have significantly higher values, such as ANS-PNS (5), Ar-Go (6) and Go-Pog (7), it is an increase in the Ar-Go lower jaw branch index (6) and provides the lower position of the angle of the mandible, which leads to a more horizontal position of the mandibular plane Mand.Plane;

more vertical arrangement of central incisors of the upper and lower jaws, which is confirmed by lower values of the angles Max1-NF (9) and Mand1-Mp (10).

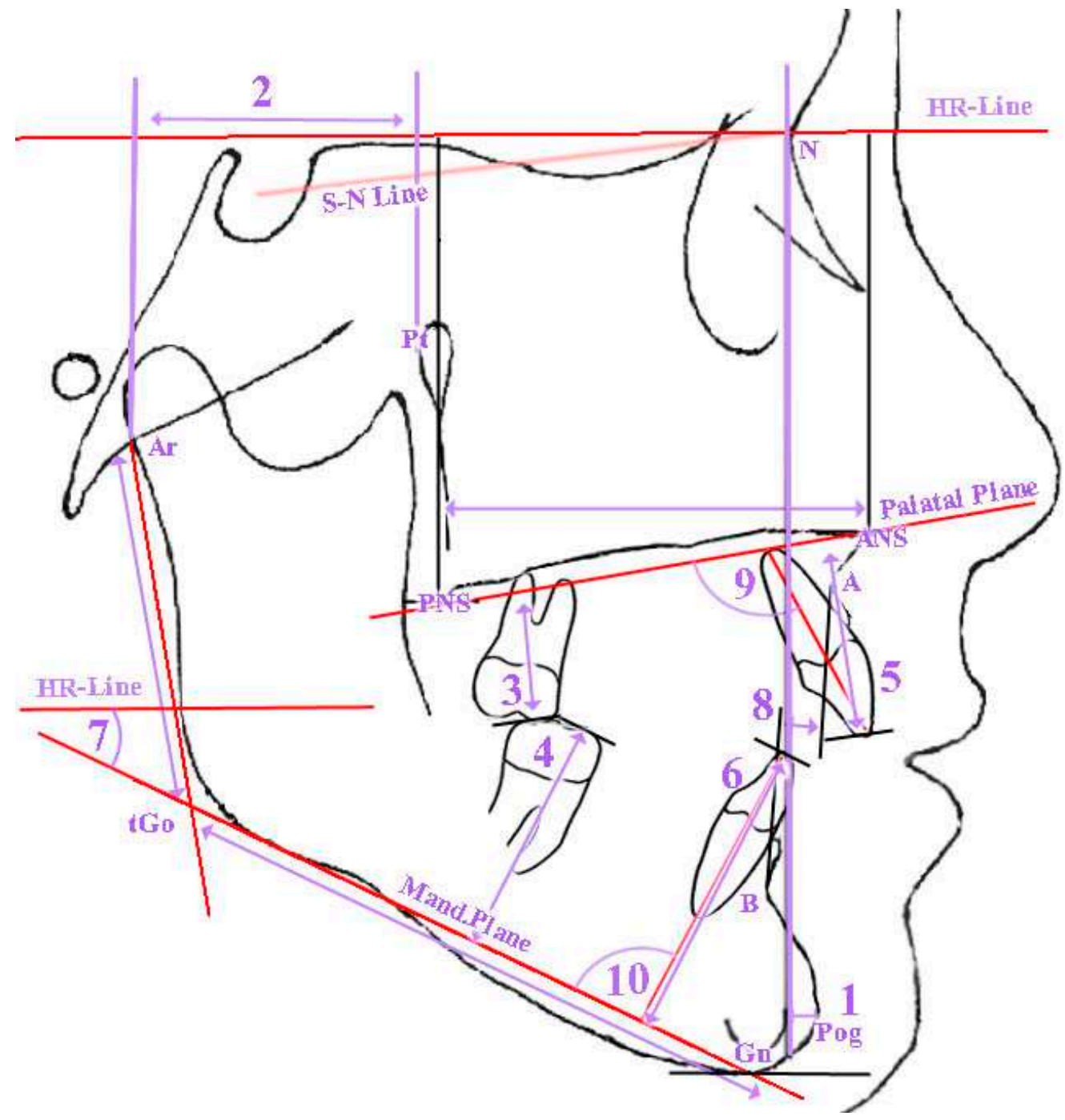

Fig. 2. Cephalometric indicators profile of Ukrainian girls with orthognathic bite by Burstone. 1 - distance N-Pog (Position of Chin); 2 - distance Ar-Pt (Posterior Section of Cranial Base); 3 -distance 6u-NF (Distance of Mesial Cusp of 6u to Palatal Plane); 4 - distance 6l-MP (Distance of Mesial Cusp of $6 l$ to Mand.Plane); 5 - distance 1u-NF (Distance of Incisal Edge of 1 u to Palatal Plane); 6 - distance 11 MP (Distance of Incisal Edge of $1 L$ to Palatal Plane); 7 - angle MP-HP (Angle of Mand. to Horizontal Plane); 8 - distance A-B (Distance of A to B on Occl. Plane); 9 - angle Maxl-NF (Angle of Axis of 1u to Palatal Plane); 10 - angle Mand1-Mp (Angle of Axis of 11 to Mand. Plane).

When analyzing the profile of Ukrainian young women with orthognathic bite, it is necessary to note the following most pronounced features of cephalometric indices by Burstone C. J. (Fig. 2): 
an increase in the distance $\mathbf{N}-\mathbf{P o g}(1)$, which characterizes the posterior position of the chin to the perpendicular N-Vert, creates a more retrograde profile;

reduction of the distance Ar-Pt (2), which characterizes the forward position of the temporomandibular joint;

reduction of the distances of the location of the first molars and central incisors of the upper and lower jaws (respectively 6u-NF (3), 6l-MP (4), 1u-NF (5) and 1l-MP (6)) in relation to the palatine and mandibular planes and decrease in distance A-B (8) is determined by decreasing the angle of MP-HP (7); more vertical arrangement of central incisors, which is confirmed by smaller values of the angles Max1-NF (9) and Mand1-Mp (10).

Analyzing the profile of Ukrainian young men and women with orthognathic bite, it is necessary to note the following most pronounced features in comparison with the values of these indicators defined by Harvold E. P. (Fig. 3):

more protruding position of the central incisors of the upper and lower jaws, as evidenced by the higher values of the interincisal angle II (4);

the decrease of the lower third of the face, which is determined by the ANS-Gn (3), occurs with its reverse location, as indicated by lower values of the TM-ANS (1) and TM-PGN (2) indices; only in Ukrainian young women there is additionally significantly higher values of the angle Ap1uAp1l-DOP (5), indicating a more forward position of the tops of the roots of the lower central incisors relative to the upper ones.

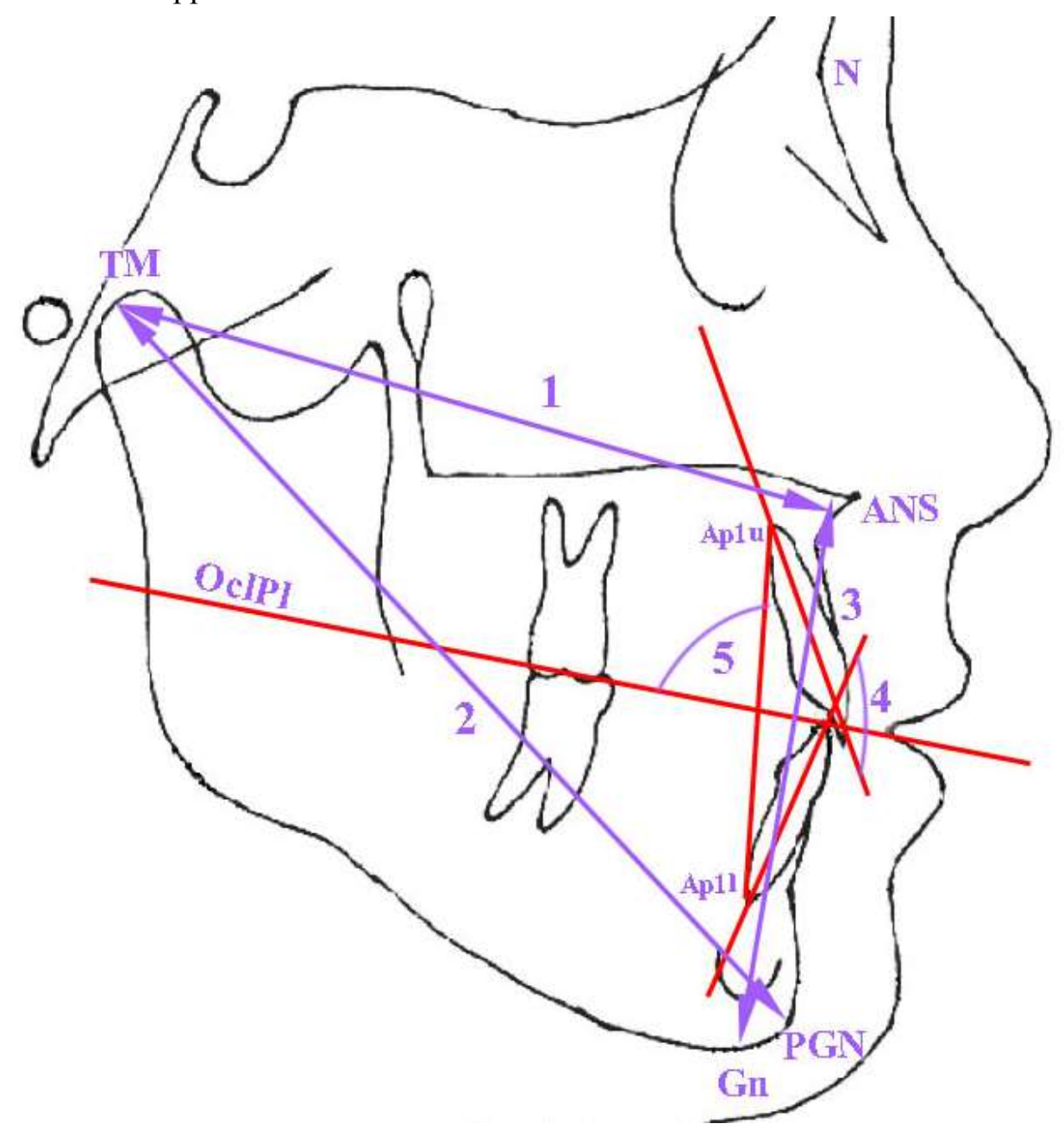

Fig. 3. Cephalometric indicators profile of Ukrainian boys and girls with orthognathic bite by Harvold. 1 distance TM-ANS (maxillary length); 2 - distance TM-PGN (mandibular length); 3 - distance ANS-Gn (Lower Face Height); 4 - angle II (Interincisal Angle); 5 - angle ApluAp1l-DOP (Angle between Occlusal

Plane and the connecting line between the root tips of the central upper and lower incisor).

When analyzing the profile of Ukrainian young men with orthognathic bite, it is necessary to note the following most pronounced features in comparison with the values of these indices determined by Ricketts R. M. (fig. 4): 
more protruding position of the lower jaw incisors, as evidenced by the larger values of the Mand1-APog angle (1) and the distance 11-APog (2);

more vertical and forward position of the upper jaw incisors, which is characterized by lower values of the angle Max1-APog (3) and higher values of the 1u-APog (4);

a more horizontal type of face development, as evidenced by the larger values of the angles NBa-PtG (5) and POr-NBa (6);

more horizontal position of the lower jaw, as indicated by larger MeGo-NPog angle (7) and lower MeGo-POr (8) angle values. The rotation of the mandibular plane occurs counterclockwise on the one hand due to the lower position of the lower jaw angle - greater values of the distance Go-CF (9) and the angle DC-Xi-Pm (10), and on the other hand, by decreasing the bite height in the frontal area - smaller angle value ANS-Xi-PM (11);

in contrast to the angular indexes indicating a more horizontal position of the lower jaw - MeGoNPog (7) and MeGo-POr (8), the position of the closure plane relative to the point $\underline{\mathbf{X i}}$ (the geometric center of the mandible branch) Xi-OcP (12) has larger values indicating either the more vertical location of the closure plane or the lower location of the point $\underline{\mathbf{X}}$. The determination of the latter is directly influenced by the low position of the lower edge of the angle of the mandible, as indicated by the larger values of the MeGo-NPog angle (7) and smaller of MeGo-POr (8) angle;

a more forward position of the foramen rotundum, as indicated by larger values of the distance P-PTV (13), lower of N-CC distance (14) and POr-CFXi (15) angle.

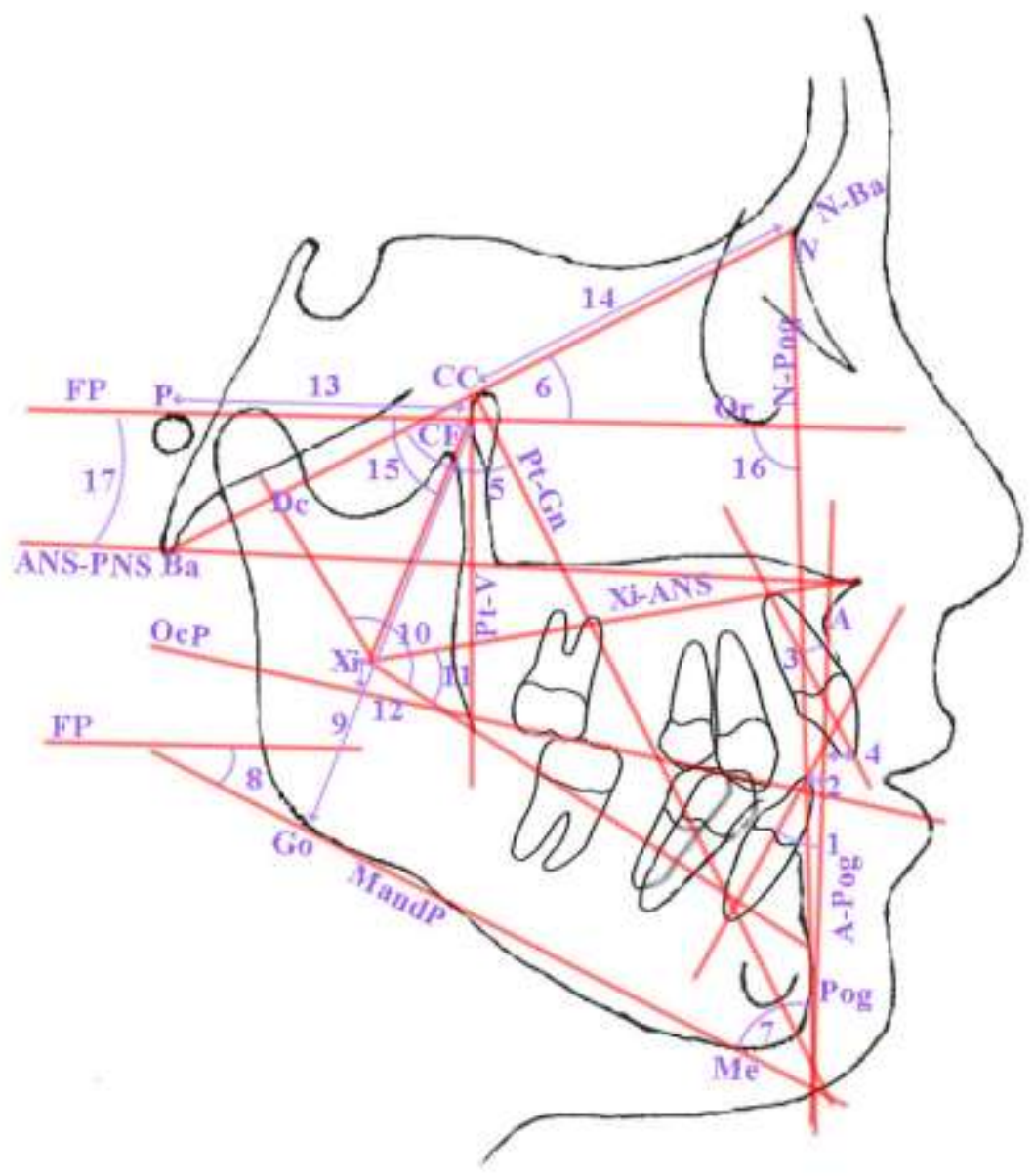

Fig. 4. Cephalometric indicators profile of Ukrainian boys and girls with orthognathic bite by Ricketts. 1 - angle Mand1-APog (Lower Incisor Inclination); 2 - distance 1l-APog (Lower Incisor Protrusion); 3 - angle Max1-APog (Upper Incisor Inclination); 4 - distance 1u-APog (Upper Incisor Protrusion);

5 - angle NBa-PtG (Facial Axis); 6 - angle POr-NBa (Cranial Deflection); 7 - angle MeGo-NPog

(Facial Taper); 8 - angle MeGo-POr (Mandibular Plane Angle); 9 - distance Go-CF (Posterior

Facial Height); 10 - angle DC-Xi-Pm (Mandibular Arc); 11 - angle ANS-Xi-PM (Lower Facial Height); 12 - distance Xi-OcP (Occlusal Plane to Ramus); 13 -distance P-PTV (Porion Location); 14 - distance N-CC (Cranial Length - Anterior); 15 - angle POr-CFXi (Ramus Position), 16 - angle NPog-POr (Facial Depth); 17 - angle POr-SpP (Palatal Plane Angle). 
When analyzing the profile of Ukrainian young women with orthognathic bite, it is necessary to note the following most pronounced features in comparison with the values of these indicators identified by Ricketts R. M. (Fig. 4):

more protruding position of the mandibular incisors, as evidenced by the larger values of the

Mand1-APog angle (1) and larger values of the distance 11-APog (2);

more vertical position of the upper jaws incisors, as evidenced by smaller values of the angle

of Max1-APog (3) and greater values of the 1u-APog (4);

lowering the height of the lower third of the face, indicating the reduction of the angle ANSXi-PM (11);

a higher location of the distal part of the closure plane relative to the geometric center of the mandible branch - point $\underline{\mathbf{X}}$, indicating a greater value of distance $\mathbf{X i - O c P}(12)$;

a more horizontal type of face development, as evidenced by the larger values of the angles

NBa-PtG (5) and POr-NBa (6);

more forward position of the bony chin is determined by lower values of the angle of the

NPog-POr (19);

we can state the rotation of the Frankfurt plane clockwise towards the basal $(\mathrm{N}-\mathrm{Ba})$, the palatal

( $\mathrm{SpP}$ is also found in the ANS-PNS) and the face (N-Pog) planes, taking into account the smaller values of angles POr-SpP (20), POr-NBa 6) and NPog-POr (19);

a more forward position of the foramen rotundum, as indicated by larger values of the distance

P-PTV (13) and lower values of the distance N-CC (14) and the angle POr-CFXi (15);

more horizontal position of the mandibular plane (Me-Go) with respect to the front plane $(\mathrm{N}$ -

Pog) is determined by the higher values of the MeGo-NPog angle (7).

Thus, when comparing the results of our study, it was established that cephalometric indices of Ukrainian young men and women with orthognathic bite obtained by methods of Burstone C. J., Ricketts R. M. and Harvold E. P. differ from similar indicators obtained by the authors of these methods in other ethnic groups $[1,2,3]$. That is why, before planning any orthodontic procedures, one can not underestimate the cephalometric norms developed for different ethnic and racial groups. This allows the orthodontist to improve the accuracy of the cephalometry by standardizing the source data and predict both the growth and outcome of the change in the parameters of the facial part of the head during the treatment.

Conclusions. The established features of the morphometric characteristics of the youth Ukrainian population by methods of Ricketts R. M., Burstone C. J. and Harvold E. P. confirm the necessity of creation and further study of normative cephalometric data for various ethnic, age and sex groups of the population.

\section{REFERENCES}

1. Athanasiou, A. E. (1997). Orthodontic cephalometry. London. Osby Wolfe.

2. Burke, C. (2015). A century of influence: Part 2. The greatest generation. American Journal of Orthodontics and Dentofacial Orthopedics, 148(2), 226-230.

3. Burstone, C. J., James, R. B., Legan, H., Murphy, G. A., \& Norton, L. A. (1979). Cephalometrics for orthognathic surgery. J. Oral. Surg., 36, 269-277.

4. Chernysh, A. V. (2018). Cephalometric studies of Ukrainian young men and women with orthognathic bite by the method of E. P. Harvold. Reports of Morphology, 2(24), 38-43.

5. Chernysh, A. V., Gunas, I. V., Gavryluk, A. O., Dmytrenko, S. V., Serebrennikova, O. A., Kyrychenko, Yu. V., \& Balynska, M. V. (2018). Cephalometric studies of ukrainian boys and girls with orthognathic bite by the method of R. M. Ricketts. World of Medicine and Biology, 2(64), 88-93.

6. Dmitriev, M. O., Chernysh, A. V., \& Chugu, T. V. (2018). Cephalometric studies of Ukrainian boys and girls with physiological bite by the method of Charles J. Burstone. Biomedical and Biosocial Anthropology, 30, 62-67.

7. Gulati, A., \& Jain, S. (2013). Comparison of dentoskeletofacial cephalometric values of Malwa population of Madhya Pradesh with other racial and ethnic groups. Journal of Pierre Fauchard Academy (India Section), 27(3), 95-101.

8. Harvold, E. P. (1974). The activator in orthodontics. St. Louis, Mo., Mosby.

9. Jamayet, N. B., Viwattanatipa, N., Amornvit, P., Pornprasertsuk, S., Chindasombatjaroen, J., \& Alam, M. K. (2014). Comparison of crown width/length ratio of six maxillary anterior teeth between different facial groups in Bangladeshi population. Int. Med. J., 21(1), 49-54.

10. Kumar, S. K., Lakshmi, A. V., Namita, S., \& Elumalai, M. (2013). Craniofacial morphologic variations and its association with hypodontia pattern (Anterior) in South Indian female population. Biosci. Biotechnol. Res. Asia, 10, 325-328. 
11. Ochoa, B. K., \& Nanda, R. S. (2004). Comparison of maxillary and mandib-ular growth. Am. J. Orthod. Dentofacial. Orthop., 125, 148-159.

12. Olsen, J. A., \& Inglehart, M. R. (2011). Malocclusions and perceptions of at-tractiveness, intelligence, and personality, and behavioral intentions. Am. J. Orthod. Dentofacial. Orthop., 140, 669-679.

13. Rahmati Kamel, M., Ostad Rahimi, A., \& Ghorbanipour, R. (2017). Evaluation of soft tissue norms on lateral cephalograms in Babol. Caspian Journal of Dental Research, 6(2), 30-34.

14. Ricketts, R. M. (1972) The value of cephalometrics and computerized technology. Angle Orthod., 42, 179-199.

15. Ricketts, R. M. (1972). A principle of arcial growth of the mandible. Angle Orthod., 42, 368-386.

16. Savakkanavar, M., Girish, K. S., Poorya, D. S., \& Reddy, S. R. K. (2015). Soft tissue cephalometric norms for orthognathic surgery in Karnataka population. Group, 5(2), 22-27.

17. Sinojiya, J., Aileni, K. R., Rachala, M. R., Pyata, J. R., Mallikarjun, V., \& Reddy, C. M. (2014). Soft tissue esthetic norms for Mahabubnagar population of southern India. Journal of clinical and diagnostic research: $J C D R, 8(1), 255-259$.

18. Sundareswaran, S., \& Ramakrishnan, R. (2016). The Facial Aesthetic index: An additional tool for assessing treatment need. Journal of orthodontic science, 5(2), 57-63.

19. Tikku, T., Khanna, R., Maurya, R. P., Verma, S. L., Srivastava, K., \& Kadu, M. (2014). Cephalometric norms for orthognathic surgery in North Indian population using Nemoceph software. Journal of oral biology and craniofacial research, 4(2), 94-103.

20. Upadhyay, J. S., Maheshwari, S., Verma, S. K., \& Zahid, S. N. (2013). Soft tissue cephalometric analysis applied to regional Indian population. National journal of maxillofacial surgery, 4(2), 159-166. 